\title{
Defining unmet clinical need across the pathway of brain tumor care: a patient and carer perspective
}

This article was published in the following Dove Press journal: Cancer Management and Research

\author{
William Sage' \\ Rocío Fernández-Méndez' \\ Anna Crofton ${ }^{2}$ \\ Michael J Gifford ${ }^{3}$ \\ Alexey Bannykh ${ }^{3}$ \\ Constantinos Chrysaphinis ${ }^{4}$ \\ Emma Tingley ${ }^{4}$ \\ Helen Bulbeck ${ }^{5}$ \\ Mita Brahmbhatt ${ }^{\prime}$ \\ John D Pickard' \\ Fiona MWalter ${ }^{6}$ \\ Andrew Brodbelt ${ }^{2}$ \\ Stephen J Price' \\ Alexis J Joannides' \\ 'Department of Clinical \\ Neurosciences, University of \\ Cambridge, Cambridge, UK; \\ ${ }^{2}$ Department of Neurosurgery, \\ The Walton Centre, Liverpool, UK; \\ ${ }^{3}$ Mountain Hare Consulting, London, \\ UK; ${ }^{4}$ The Brain Tumour Charity, \\ Farnborough, UK; ${ }^{5}$ Brainstrust, Cowes, \\ Isle of Wight, UK; ' ${ }^{6}$ Primary Care \\ Unit, Department of Public Health \\ and Primary Care, University of \\ Cambridge, Cambridge, UK
}

Correspondence: William Sage Department of Clinical Neurosciences, University of Cambridge, Box 167,

Addenbrookes Hospital, Hills Road,

Cambridge CB2 0QQ, UK

Tel +44 7725323404

Email will.a.sage@gmail.com
Objective: The aim of this study was to determine the experience of patients with brain tumors and their carers across distinct parts of their treatment pathway and identify their views on potential service gaps in need of addressing.

Methods: A structured survey was administered at patient workshops across the UK and online through a charity newsletter. Answers to closed questions were analyzed using descriptive statistics, and open questions were examined using techniques of inductive content analysis.

Results: A total of 136 survey responses were received, representing patients with a variety of diagnoses and geographical locations (30 counties). There was a wide range of opinions on the provision of current neuro-oncology services. Key themes identified included a perceived lack of information provision, a gap in postdischarge psychological and neuropsychological supports, and an unmet willingness for involvement in research.

Conclusion: This national survey enhances our knowledge of current patient and carer experience within neuro-oncology services. A number of areas of unmet clinical need are highlighted providing a basis for informing future patient-centered service improvements and research.

Keywords: patient experience, brain cancer, brain tumors, neuro-oncology pathway

\section{Introduction}

The impact of a diagnosis of a brain tumor is significant and can affect the quality of life through disease progression and the effects of treatment. ${ }^{1,2}$ The effects of a brain tumor can manifest in many ways, from neurological disability, including motor, speech, visual, and cognitive deficits, to financial concerns and uncertainty regarding the disease course and eventual outcomes.

Best practice clinical management of brain tumors requires a multidisciplinary approach, requiring patients to have multiple consultations with various health care professionals throughout the course of their disease. ${ }^{3}$ It follows that to deliver care to meet patient needs adequately requires robust means of evaluating service quality and effectiveness. Furthermore, priorities for patients with cancer are tumor-specific, ${ }^{4}$ with each diagnosis having its own needs with regard to the service provided. It is therefore important to evaluate patient care with this in mind, as prescription of generic cancer service guidelines may not wholly meet the needs of all patients.

Currently, the patient's perspective and experience of current neuro-oncology services spanning their treatment pathway are under-reported in the scientific literature. As early as 1995, the Calman-Hine report recommended that services should be patientcentered with readily available and accessible information. ${ }^{5}$ This management approach 
was re-iterated in 2006 in the National Institute for Health and Care Excellence (NICE) guidance for "improving outcomes for people with brain and other CNS tumors". ${ }^{6}$

While restructuring of cancer services has been shown to reduce emergency admissions, length of hospital stay, and improved survival in brain tumors, ${ }^{7}$ both national and local surveys have identified areas in which patient experience could be improved. The Cancer Patient Experience Survey national report 2015 (of which CNS tumors represented $<1 \%$ of patients) showed that despite improvements in cancer care since the previous report, there remain inconsistencies ${ }^{8}$; for example, information provision varies throughout disease course and inpatient care appears to be more positively experienced than health services at home. Recent reports on the patient's experience of CNS tumors identified significant variability across the services provided and satisfaction with these. ${ }^{9-11}$ In particular, they recognized that patients felt low levels of psychological support, rehabilitation, and supportive care as well as some patients experienced difficulties with the understanding of information provided at diagnosis. These findings were confirmed by a local report within the Anglia Cancer Network, again highlighting the need for wider support services. $^{11}$

Against this background, we conducted a nationwide survey to explore the experience of patients with brain tumors and their carers across distinct parts of their treatment pathway, ranging from initial presentation and diagnosis to specialist treatment and rehabilitation. Through this approach, we sought to 1) systematically identify service needs from a patient perspective and 2) evaluate the potential utility of a number of proposed quality improvement interventions in this area.

\section{Methods}

\section{Questionnaire design and administration}

A structured survey questionnaire was developed to address distinct aspects of neuro-oncology service provision, in line with the study objectives and previous surveys in this area $^{9,11}$ (Supplementary materials A). Individual items were determined through an iterative process involving multiple stakeholders including neurosurgeons, oncologists, nurse specialists, and patient representatives, thus ensuring face validity of the survey.

The survey included a section for demographical information followed by 32 closed questions about the following four relevant domains: 1) initial diagnosis, 2) first specialist appointment, 3) on-going care and rehabilitation, and 4) involvement in research. Each domain was followed by an open question to allow participants to comment on each dimension of the pathway. Closed questions included multiple-choice questions (with only one or more than one possible answers), as well as Likert-type scale items where participants were asked to rate each part of the pathway, including potential improvements that could be made at each stage, on a 1-5 scale. The survey could be completed either online or in a paper format.

\section{Study sample}

A convenience sample of patients with brain tumors, or their carers, was used for the study. Participants were recruited in the following two ways: 1) patients or carers were invited to participate during six workshops with brain tumor patients across the UK (carried out in Cambridge, London, Manchester, and Liverpool, attended by 55 patients), where they completed the questionnaire in a paper format, and 2) the Brain Tumour Charity included an invitation to complete the survey online through a link using SurveyMonkey ${ }^{\circledR}$ in their newsletter, circulated via their mailing list between July and December 2015 . When completed by a carer, the survey was answered as a surrogate on behalf of the patient. ${ }^{12}$

\section{Ethical approval}

The format and conduct of the survey were approved by the review boards of the two participating charities (The Brain Tumour Charity, Farnborough, Hampshire, UK, and Brainstrust, Cowes, Isle of Wight, UK) through which participants were recruited. All responses were recorded anonymously, and participants were informed that by completing the questionnaire, they were consenting to participate.

\section{Analysis}

Each of the closed questions was examined in isolation to assess for trends in answers. As responses to each question were not mandatory, nonresponses were acknowledged in further analysis. Results are expressed as the absolute number of responders and percentage proportion of the entire cohort unless stated otherwise. Where appropriate, answers were reviewed by the subgroup of tumor type. For responses on an ordinal scale (1-5), responses were grouped into positive (4-5), negative (1-2), or neutral (3) responses (refer Supplementary materials A for exact response items).

Techniques of inductive content analysis were used to examine emerging themes from the qualitative data of the four free-text questions. ${ }^{13}$ Open coding (labeling) was utilized to analyze text data, thus allowing categories of data to be generated directly from the answers. Once a code had been identified, it was used further to code subsequent answers. 
The categories were grouped into broader concepts to identify emerging themes. Analyses were performed independently by two investigators, and any divergent opinions were agreed by consensus.

\section{Results \\ Study population}

A total of 136 responses to the survey were received, including $55(40 \%)$ from the paper-based questionnaire and 81 $(60 \%)$ through the online version. Of all questionnaire responses, $98(72 \%)$ responses were completed by patients themselves, while the remaining 48 (28\%) responses were completed on behalf of the patient by a carer.

The majority of responders were female (male:female, 40 [29.4\%]:94 [69.1\%], two nonresponders), under the age of 65 years (122; 92\%), and identified as white British (126; $93 \%)$. The three commonest diagnoses were high-grade glioma (HGG) $(54 ; 40 \%)$, low-grade glioma (LGG) $(31 ; 23 \%)$, and meningioma $(28 ; 21 \%)$. Two patients were identified as having more than one tumor, for example, both an HGG and a meningioma, resulting in a total of 137 tumors across the 135 patients who responded to the question. There was a wide geographical variation in responses received, with Scotland (19, 14\%), London (17, 13\%), Manchester (14, 10\%), Cambridgeshire (14, 10\%), and Liverpool (7, 5\%) representing the largest regions by responder number. A summary of sociodemographic data and diagnosis is shown in Table 1.

\section{Presentation and diagnosis Initial diagnosis \\ Quantitative data}

The first domain of the survey explored the period prior to diagnosis, including mode of presentation to the health service, presenting symptoms, and their time course. There was a wide variation in time from initial diagnosis to questionnaire completion, representing patients at different stages within the neuro-oncology pathway. A total of $25(18 \%)$ patients had been diagnosed within the last year and $39(29 \%)$ patients had been diagnosed more than 5 years prior to completing the questionnaire (Figure 1A).

The most common pathway to diagnosis was following an emergency presentation to hospital (Figure 1B). The proportion of patients who presented this way was higher in intrinsic tumors, with $28(52 \%)$ of HGG and $15(48 \%)$ of LGG presenting by this mechanism (Table 2). Responses in other categories consisted most commonly of referrals for
Table I Responders' ( $n=\mid 36)$ demographics by gender, age, ethnicity, education, and tumor type

\begin{tabular}{|c|c|}
\hline & n (\%) \\
\hline \multicolumn{2}{|l|}{ Gender } \\
\hline Male & $40(30)$ \\
\hline Female & $94(69)$ \\
\hline No response & $2(I)$ \\
\hline \multicolumn{2}{|l|}{ Age (years) } \\
\hline$<35$ & $29(2 \mathrm{I})$ \\
\hline $35-44$ & $32(24)$ \\
\hline $45-54$ & $32(24)$ \\
\hline $55-64$ & $31(23)$ \\
\hline $65-74$ & II (8) \\
\hline No response & $\mathrm{I}(\mathrm{I})$ \\
\hline \multicolumn{2}{|l|}{ Ethnicity } \\
\hline White British & $126(93)$ \\
\hline Asian or Asian British & $2(1)$ \\
\hline Black or Black British & $I(I)$ \\
\hline Chinese & $I(I)$ \\
\hline Others & $5(4)$ \\
\hline No response & $\mathrm{I}(\mathrm{I})$ \\
\hline \multicolumn{2}{|l|}{ Level of education } \\
\hline None & $7(5)$ \\
\hline GCSE, O-level, or CSE & $37(27)$ \\
\hline A-level or equivalent & $30(22)$ \\
\hline Vocational & $10(7)$ \\
\hline Undergraduate degree & $26(19)$ \\
\hline Postgraduate degree & $21(15)$ \\
\hline No response & $5(4)$ \\
\hline \multicolumn{2}{|l|}{ Geographical location } \\
\hline Scotland & $19(14)$ \\
\hline London & $17(13)$ \\
\hline Manchester & $14(10)$ \\
\hline Cambridgeshire & $14(10)$ \\
\hline West Midlands & $7(5)$ \\
\hline Liverpool & $7(5)$ \\
\hline Yorkshire & $6(4)$ \\
\hline Hampshire & $5(4)$ \\
\hline Essex & $4(3)$ \\
\hline Wales & $3(2)$ \\
\hline Oxfordshire & $3(2)$ \\
\hline Kent & $3(2)$ \\
\hline Others $^{\mathrm{a}}$ & $25(18)$ \\
\hline No response & $9(7)$ \\
\hline \multicolumn{2}{|l|}{ Diagnosis } \\
\hline HGG & $54(40)$ \\
\hline LGG & $31(23)$ \\
\hline Meningioma & $28(2 \mathrm{I})$ \\
\hline Metastatic tumor & $I(I)$ \\
\hline Do not know & $4(3)$ \\
\hline Others & $19(14)$ \\
\hline No response & $I(I)$ \\
\hline
\end{tabular}

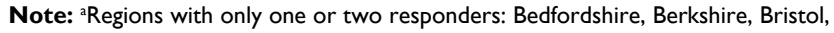
Cheshire, Derbyshire, Devon, Dorset, Hertfordshire, Isle of Wight, Lancashire, Leicestershire, Lincolnshire, Norfolk, Northern Ireland, Northumberland, Nottinghamshire, Staffordshire, and Sussex.

Abbreviations: CSE, Certificate of Secondary Education; GCSE, General Certificate of Secondary Education; HGG, high-grade glioma; LGG, low-grade glioma. 


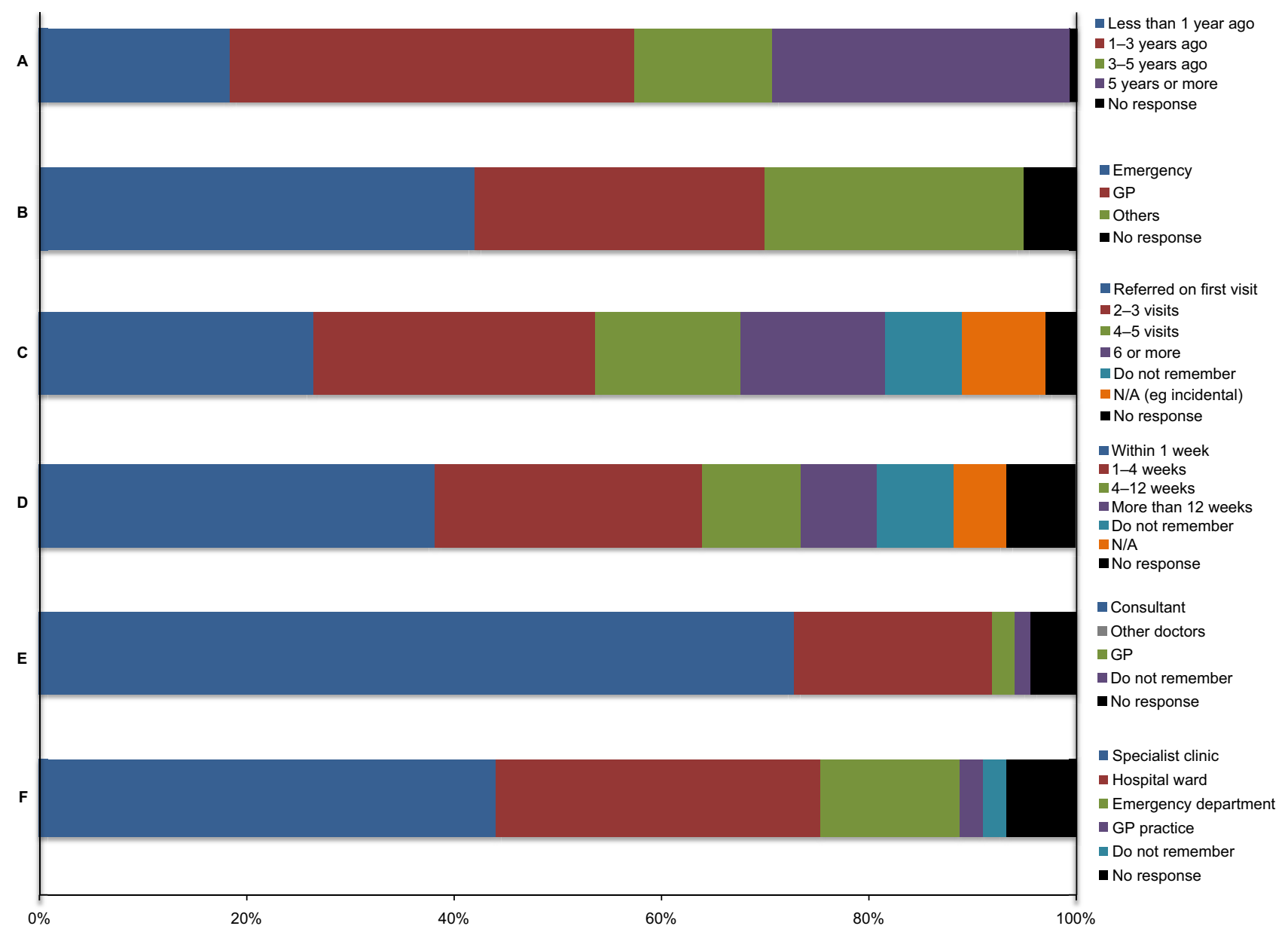

Figure I Responses to questions relating to initial diagnosis.

Notes: Questions from survey: (A) When were you first diagnosed with a brain tumor? (B) How were you first diagnosed? (C) How many times did you visit the hospital/ your GP with the above symptoms before being referred for a scan? (D) How long did it take between being referred for a scan and this taking place? (E) Who was your diagnosis given by? (F) Where were you informed of your diagnosis?

Table 2 Mechanism of initial presentation for each tumor type

\begin{tabular}{|c|c|c|c|c|}
\hline \multirow[t]{2}{*}{ Tumor type } & Presented as emergency & Referred by GP for scan & Others & No response \\
\hline & n (\%) & n (\%) & n (\%) & n (\%) \\
\hline High-grade glioma & $28(52)$ & $14(26)$ & $9(17)$ & $3(6)$ \\
\hline Low-grade glioma & $15(48)$ & $7(23)$ & $9(29)$ & $0(0)$ \\
\hline Meningioma & $9(32)$ & $7(25)$ & $10(36)$ & $2(7)$ \\
\hline Metastases & $0(0)$ & $0(0)$ & $I(100)$ & $0(0)$ \\
\hline Do not know & $\mathrm{I}(25)$ & I (25) & $2(50)$ & $0(0)$ \\
\hline Others & $4(2 I)$ & $9(47)$ & $5(26)$ & I (5) \\
\hline
\end{tabular}

imaging from other hospital specialties, including ophthalmology and ENT.

There was a variation in the timing from the initial presentation to a referral for imaging, with $36(27 \%)$ responders referred for a scan on their first encounter with the health service relating to this condition, $37(27 \%)$ responders for a scan within two to three visits, and the remaining $59(43 \%)$ responders referred for a scan after three visits or more
(Figure 1C). Overall, scans were reported to occur in a timely manner after initial imaging referral. A total of 52 (38\%) patients received their initial scan within a week and a further 35 (26\%) patients had a scan within 4 weeks (Figure 1D).

Common presenting symptoms that were individually present in more than $25 \%$ of patients included headache (61, $45 \%)$, poor balance $(41,30 \%)$, seizures $(40,29 \%)$, and visual disturbance $(39,29 \%)$. A total of 37 (27\%) patients presented 
with one symptom, 31 (23\%) patients presented with two symptoms, $18(13 \%)$ patients presented with three symptoms, and $46(34 \%)$ patients presented with four or more symptoms. Three tumors were also diagnosed incidentally (Figure 2).

\section{Qualitative data}

A total of 59 participants answered the open question on the events around their initial diagnosis (Supplementary materials B). The following themes emerged from their answers. These themes help to contextualize the responses to the closed questions above.

Referrals to a specialist are often seen as delayed and negative, often due to initial "wrong" diagnosis in primary care: in descriptions of their referral process, both via primary care and as an emergency, patients describe their referrals as a long and delayed process. Often described are first symptoms being misinterpreted and diagnosed as stress or anxiety. On some occasions, patients were given a diagnosis, for example, vertigo, migraine, and diabetes. Comments on timing of the referral process involved its length including descriptions such as "several visits" and timeframes varying from weeks to years.

It took 4 months from first onset of symptoms; including 5 weeks in hospital undergoing tests \& investigations. [Surrogate, Male, $\mathrm{HGG}]$

Kept getting sent home despite concerns, vertigo, migraine, anxiety. Mum even told gp she was concerned it was a brain tumour. Dad cared me upstairs to gp appointment when my legs gave way. No one listened we were fobbed off. [Surrogate, Male, Ependymoma]

To avoid delays, some patients spoke of using private health care to achieve faster imaging and diagnosis. In some instances, patients believed there was a "reluctance" of the health care professional to refer them for further investigations or to a specialist.

There were some cases that commented on the referral process being fast. A few described a positive experience

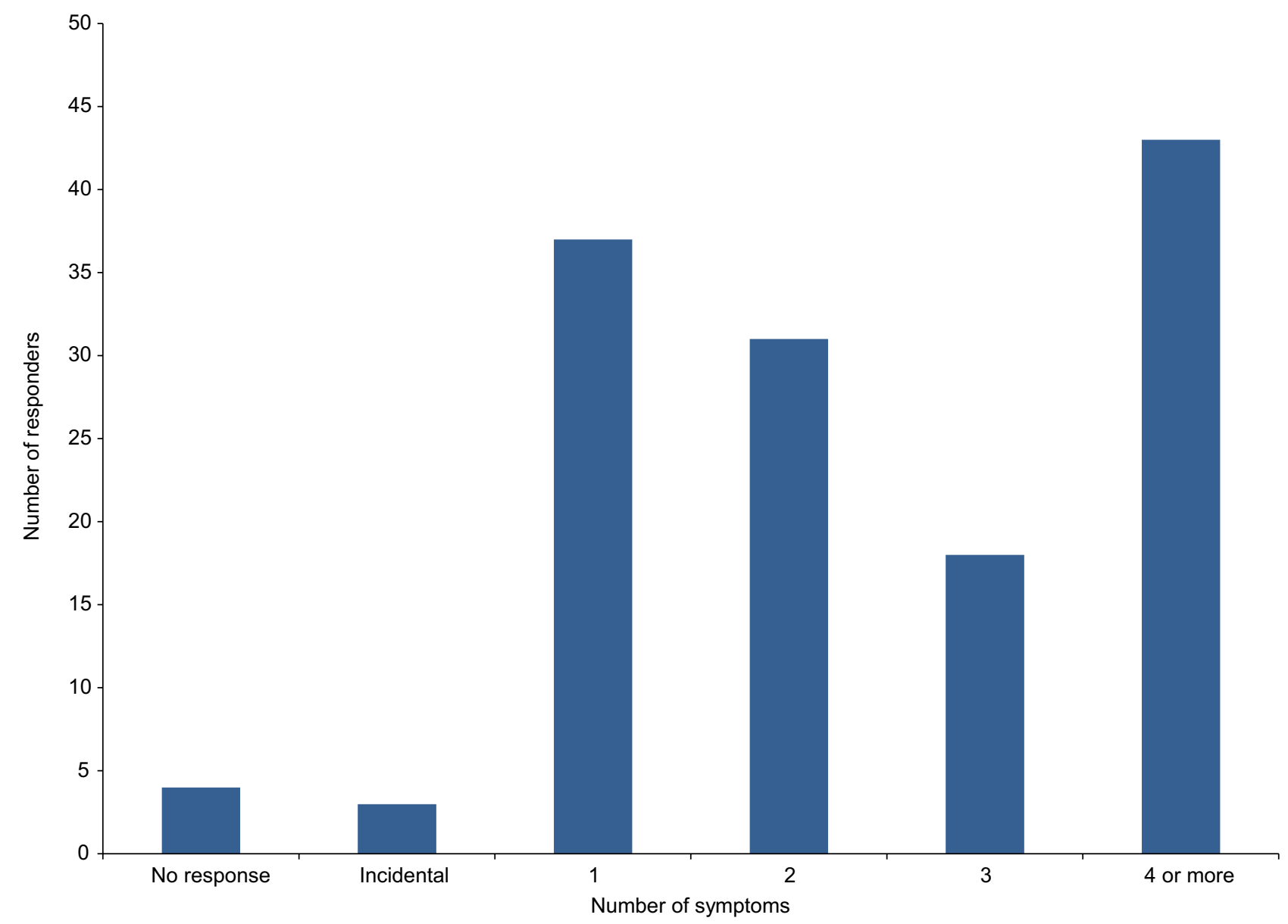

Figure 2 Number of presenting symptoms of each responder. 
with the referral process, although none of these cases went through a primary care route.

I was lucky, I didn't have a GP so my optician sent me straight to hospital, the process would have been much slower via a GP. [Patient, Female, Meningioma]

Everything happened very quickly, from collapse and visit to A\&E sunday, immediate scan, sent to [hospital] sunday night + more scans, diagnosed by neurosurgeon on Monday, surgery on Wednesday, discharged on Friday.

[Surrogate, Female, HGG]

\section{Communication of diagnosis is often felt as a negative experience by patients or carers}

This aspect spanned from the type of health care professional providing the diagnosis (not being a specialist or not the professional the patient was expecting to provide the diagnosis) to the attitude of the health care professional (described as uninterested or insensitive on a number of occasions). Mode of provision of diagnosis was often viewed as inappropriate; examples of this included phone calls or messages or following a long wait in Accident and Emergency late at night. Some patients described needing to chase for the outcomes of investigations.

Was given the news while still dazed and confused and without any close support. The news was delivered fairly

bluntly by the registrar. [Patient, Male, LGG]

A minority of patients described a positive experience with how their diagnosis was communicated. This included the speed of the communication of the diagnosis following admission, the professional attitude of the professional giving the diagnosis, and the information given at this stage.
Information provided on diagnosis is often felt as insufficient, difficult, or overwhelming by patients or carers

Numerous comments revealed that information given at this time was insufficient or lacking. Other responses stated that when information was given, this was felt to be overwhelming and comments included not having someone to talk to or no support mechanisms being in place following diagnosis.

Could have given info to take away as were given nothing to read/take home. [Surrogate, Male, HGG]

The dr was very sensitive when giving diagnosis but used medical terms not language i could understand. [Surrogate, Female, LGG]

\section{First specialist appointment}

Quantitative data

Following the initial diagnostic scan, 110 (81\%) patients were seen at a specialist clinic within 6 weeks, with nearly half $(n=54)$ of these being seen within 1 week. Despite prompt scheduling, patients reported that information provided during this period was limited. Only 38 (28\%) patients responded positively, with $57 \%$ patients giving neutral $(n=13)$ or negative $(n=47)$ responses about the information provided prior to the appointment (Table 3 ).

For the majority of patients, the diagnosis was given by a consultant $(99,73 \%)$ in either a specialist clinic $(59,43 \%)$ or a hospital ward (42,31\%) (Figure 1E). Most of the people responded positively to both how well their symptoms were addressed in the initial appointment, with 79 (58\%) patients giving a positive response, $20(15 \%)$ patients giving a neutral response, and the remainder giving a negative response. Furthermore, $88(65 \%)$ patients felt that they were given a good

Table 3 Satisfaction with different areas of the clinical pathway

\begin{tabular}{|c|c|c|c|c|c|}
\hline \multirow[t]{2}{*}{ Question } & $\begin{array}{l}\text { Positive } \\
\text { response }\end{array}$ & $\begin{array}{l}\text { Neutral } \\
\text { response }\end{array}$ & $\begin{array}{l}\text { Negative } \\
\text { response }\end{array}$ & $\begin{array}{l}\text { Not } \\
\text { applicable }\end{array}$ & $\begin{array}{l}\text { No } \\
\text { response }\end{array}$ \\
\hline & n (\%) & n (\%) & n (\%) & n (\%) & n (\%) \\
\hline Before seeing a specialist, how well were you updated/kept informed? & $38(28)$ & $17(13)$ & $60(44)$ & $14(10)$ & $7(5)$ \\
\hline At your first appointment, how well were your symptoms addressed? & $79(58)$ & $20(15)$ & $21(15)$ & - & $16(12)$ \\
\hline $\begin{array}{l}\text { At your first appointment, how much opportunity did you get to ask } \\
\text { questions? }\end{array}$ & $88(65)$ & $12(9)$ & $22(16)$ & - & $14(10)$ \\
\hline $\begin{array}{l}\text { At the first appointment, how well did you understand the } \\
\text { information provided? }\end{array}$ & $50(37)$ & $4 \mid(30)$ & $31(23)$ & - & $14(10)$ \\
\hline $\begin{array}{l}\text { At the time of your first appointment, were you provided with details } \\
\text { of a contact worker? (If yes, how contactable were they?) }\end{array}$ & $31(23)$ & $7(5)$ & $17(13)$ & $67(49)$ & $14(10)$ \\
\hline How useful did you find the rehabilitation support received? & $37(27)$ & $12(9)$ & $35(2)$ & - & $52(38)$ \\
\hline
\end{tabular}


opportunity to ask questions (Figure 1F). However, patients were less positive about their understanding of the information provided at this stage. A total of $50(37 \%)$ patients gave positive responses to this question, $41(30 \%)$ patients gave neutral responses, and a further $31(23 \%)$ patients gave negative responses.

With regard to further contact opportunities, 67 (49\%) patients said that they were not given the details of a key worker at the time of their initial appointment. Of those who were given a key worker (55), 24 patients found them difficult to contact (negative or neutral response).

\section{Qualitative data}

Mixed views were also reported by 37 responders making further comments on the first specialist appointment.

Overall comments regarding the first specialist appointment were often negative. In the free-text descriptions, this negative experience was as a result of professionals' attitudes, insufficient information provision, or a lack of support following the appointment. These results are expanded in the following themes that emerged.

\section{Information provided during the first appointment with the specialist is often felt as insufficient or challenging by patients or carers}

This was described as a result of both insufficient information and the difficult nature of receiving information at this stage. Comments made included those such as words being too technical and a lack of time or opportunity to ask the right questions. For some, the information was too challenging and understanding the information was an issue.

Left my husband and I googling "glioma" and learning what it meant through Internet research. Very frightening. [Patient, Female, LGG]

\section{Emotional response to diagnosis is often of shock}

The most common emotional response was shock. Other responses that were mentioned included fear, scare, terror, and sadness.

I was not given much information about the tumour or pos-

sible treatments. i was in shock so i don't know how useful

it would have been anyway. [Surrogate, Female, LGG]

Patients' or carers' views on their interaction with health care professionals during the first appointment with the specialist vary, for some being negative and for some being positive.
Positive experiences involved professionals being sincere and sensitive, and being viewed as willing to help and listening well. Negative experiences were descriptions of being rushed, a view the health care professionals were insensitive, and a feeling of being confused by the interaction.

Originally seen by ENT consultant who very rudely stated I had a glioma and needed to see neurology but gave no other explanation. [Patient, Female, LGG]

Neurosurgeon was very informative and sensitive when delivering such bad news. [Surrogate, Female, HGG]

\section{Treatment and post-treatment care \\ Treatment}

The majority of responders received some form of treatment, with only 13 (five LGG, four meningioma, two HGG, one other, and one unknown) being managed with surveillance alone. The majority of patients $(103 ; 76 \%)$ had undergone surgery. Higher numbers of those with HGG received chemotherapy and radiotherapy.

\section{On-going care and rehabilitation Quantitative data}

Each responder was asked which areas of care they received information on following discharge. A total of $78(57 \%)$ responders received information on their diagnosis, and 68 $(50 \%)$ responders received information on their treatment. Information on support groups, financial support, and charities was less commonly provided (20 [15\%], 14 [10\%], and 20 [15\%], respectively) (Figure 3).

Following discharge from treatment, a large proportion of patients, $52(38 \%)$, felt that they received no additional support. Where responders stated that support was provided, this was mainly in the form of physiotherapy, 29 (26\%), and occupational therapy, 24 (22\%). Psychological support and neuropsychology following treatment were reported only by $10(7 \%)$ and $14(10 \%)$, respectively.

When asked to report on how useful the support provided was, 37 of the $84(44 \%)$ responders found the rehabilitation support they received to be useful, a further $12(14 \%)$ responders were neutral regarding their support, and 35 (42\%) responders responded negatively about the support (Table 3 ). A perceived gap in support provision was most apparent in the domains of psychological support and neuropsychology, with 53 of the 95 (56\%) responders feeling that they would have benefited from psychological support and $21(22 \%)$ from neuropsychology (Figure 4). Only 33 of the 107 (31\%) patients received a care plan on discharge from treatment. Of 


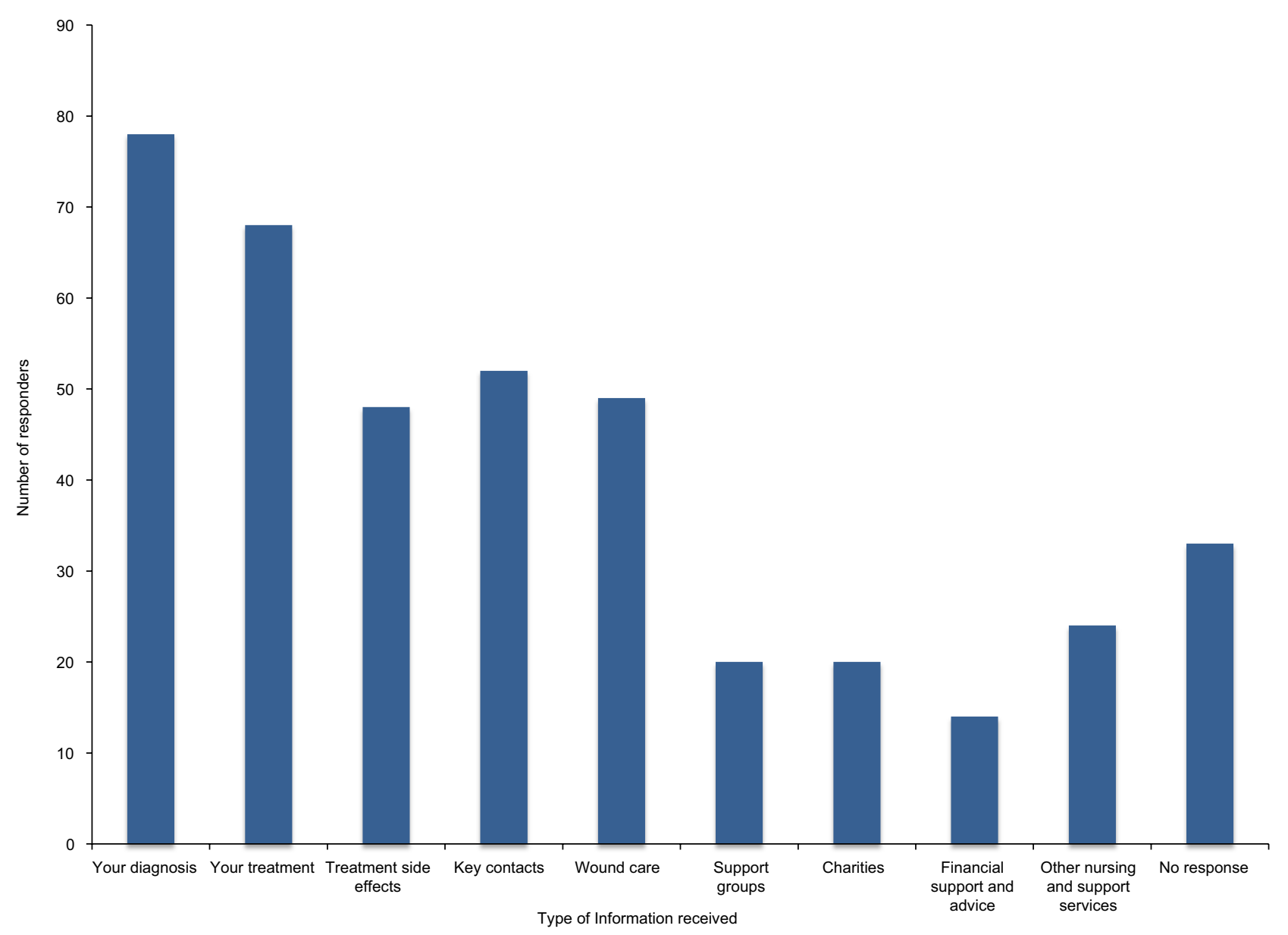

Figure 3 Information provided following discharge from treatment.

those who did, the majority (29/33) felt that it was suitable for their needs (Figure 5A).

\section{Qualitative data}

There were a further 23 responders who gave answers to open questions regarding on-going care and rehabilitation (Supplementary materials B).

\section{Lack of information regarding follow-up services that were available}

A common description was that information provided to the patient was often lacking or insufficient. This included comments on the communication of this information to the patient. Patients reported feeling the need to contact support services directly for the engagement or requirement of the patient to find information for themselves. Communication and information provision between services was also raised as an issue, with this viewed as being a possible limiting factor in patients' follow-up care.

Follow up is very disjointed and requires a lot of input from me to coordinate information and specialists. [Patient, Female, LGG]

\section{Support services and follow-up were seen as generally lacking} A number of comments referred to specific services they felt were not provided, for example psychological services. A lack of services was often seen as related to a geographical region, such as "nothing in area" and "rural service should have no excuse".

I was discharged with a promise of home visits from physio and ot as $i$ am a mum of 2 who was discharged home with a severe left sided weakness. It was 7 months before $i$ was seen as i was not a priority. [Patient, Female, LGG] 


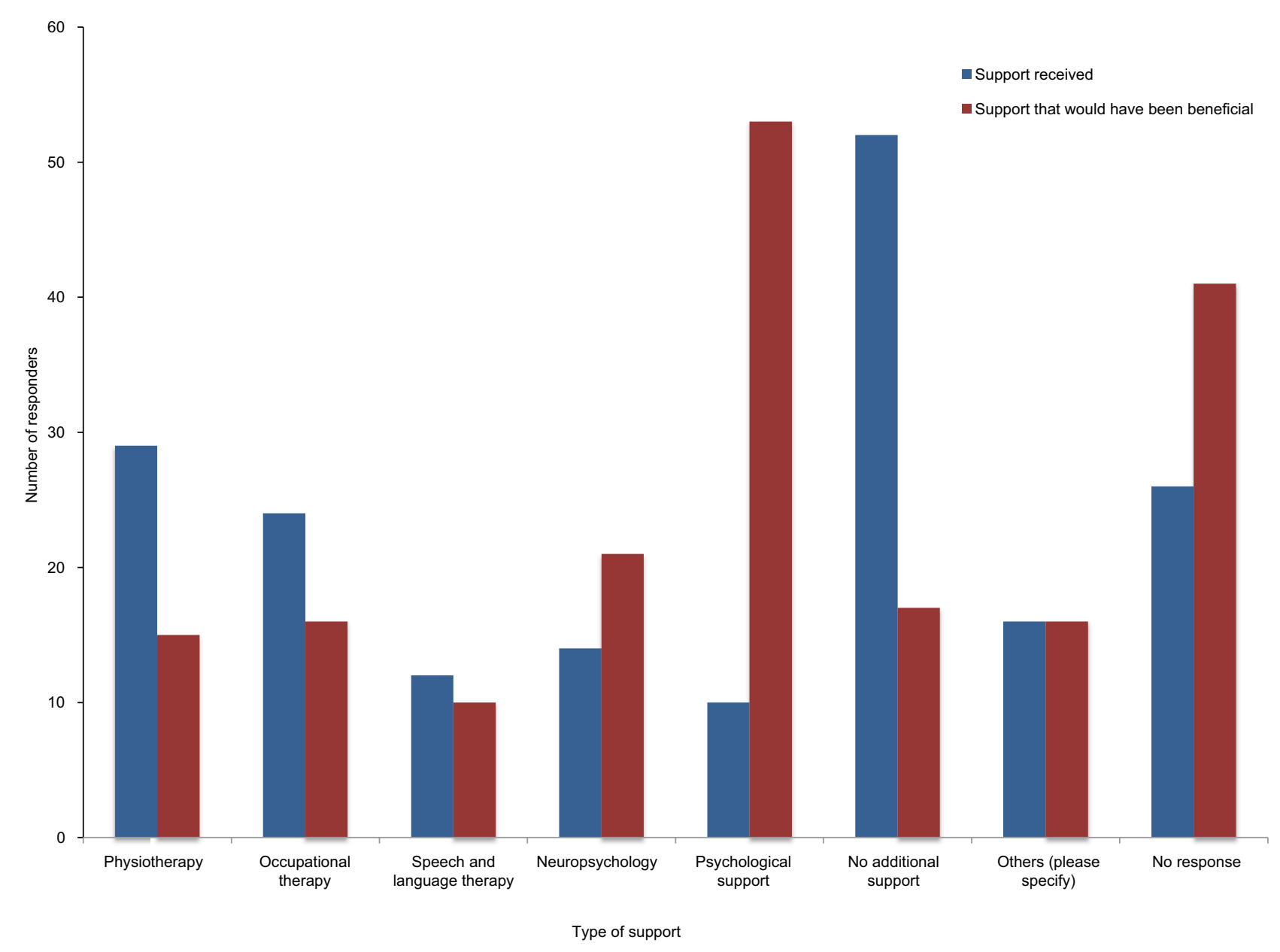

Figure 4 Differences in support received and what was felt would be beneficial.

\section{Participation in research and useful areas for development \\ Research \\ Quantitative data}

The majority of patients, 86 (63\%), reported that they had not been involved in any studies or clinical trials related to their diagnosis and 75 (55\%) patients reported that they did not have research discussed with them at any point during their treatment (Figure 5B and C).

Despite this, a large proportion of patients $(94,69 \%)$ reported that they would be willing to be included in a prospective patient register enabling them to be contacted about potential research for which they could be eligible for (Figure 5D). In line with this, 88 (65\%) patients thought that a research register informing them about such studies would be a useful development (Table 4).

Most patients also responded positively to being approached for participation in research. While most were happy with being contacted for recruitment after being provided information about a particular study $(81 \%, 74 / 91$ responders), a significant number were also happy to be contacted by the research team directly about eligible studies without prior specific consent (75\%, 71/94 responders).

\section{Qualitative data}

Free-text responses regarding the creation of a patient research register were overall positive in line with the above findings. A total of 14 further responses were given to this question (Supplementary materials B), and a limited number of those responding either had been involved in research or had it discussed with them.

\section{A research register is described as a needed and an important resource}

The majority of patients reported that they felt a register would be "vital" with a number of patients expressing 


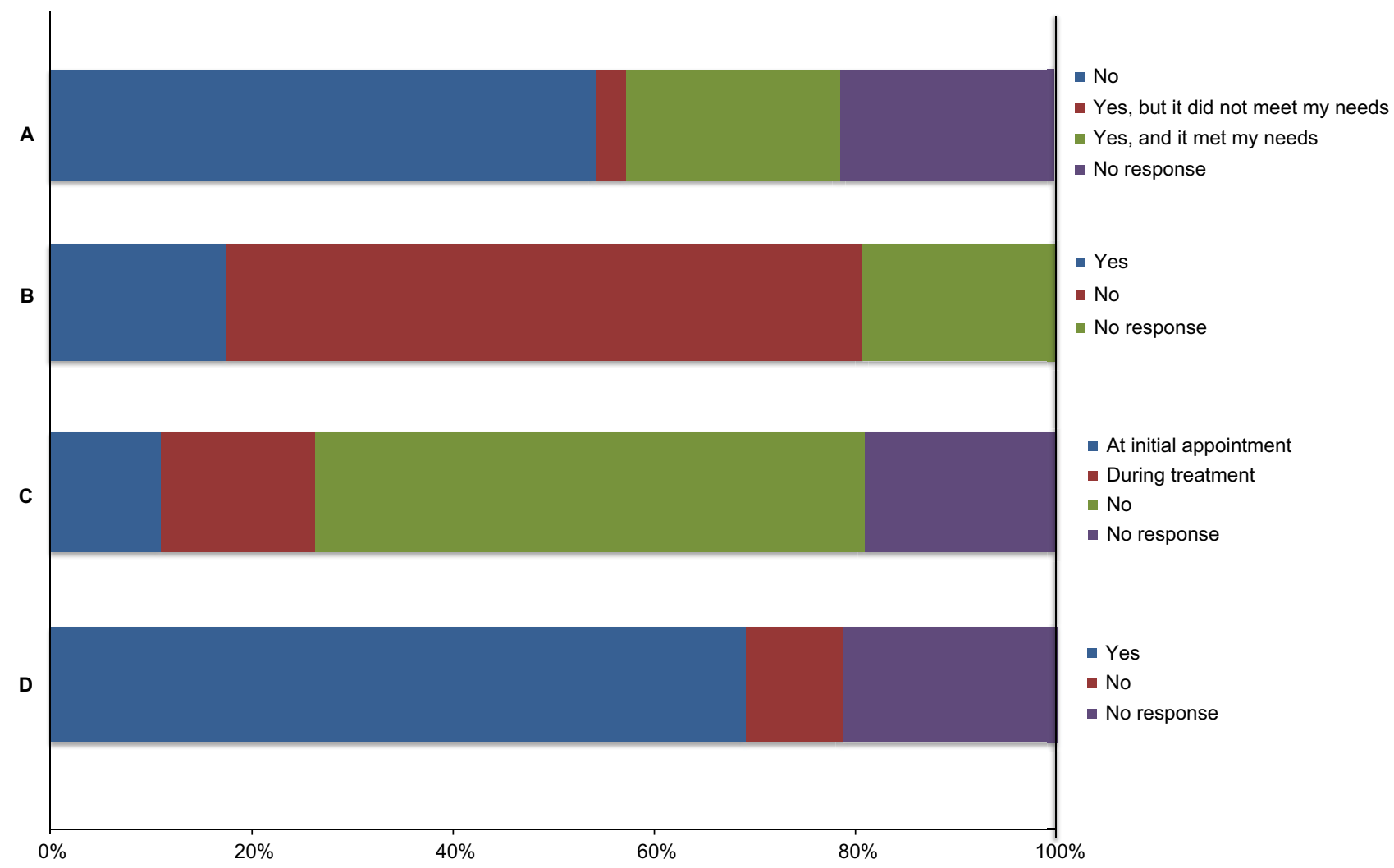

Figure 5 Responses to questions relating to care plans and involvement in research.

Notes: Questions from survey: (A) Following discharge from treatment, did you receive a personalized care plan to suit to your needs? (B) Have you participated in a study or clinical trial related to your tumor diagnosis? (C) Was involvement in research discussed with you at any point? (D) Would you be willing to be included in a patient register to inform you about future studies you may be eligible for?

Table 4 Willingness to be involved in research

\begin{tabular}{|c|c|c|c|c|}
\hline \multirow[t]{2}{*}{ Question } & $\begin{array}{l}\text { Positive } \\
\text { response }\end{array}$ & $\begin{array}{l}\text { Neutral } \\
\text { response }\end{array}$ & $\begin{array}{l}\text { Negative } \\
\text { response }\end{array}$ & $\begin{array}{l}\text { No } \\
\text { response }\end{array}$ \\
\hline & n (\%) & n (\%) & n (\%) & n (\%) \\
\hline $\begin{array}{l}\text { How useful would a patient register informing about eligible studies be? } \\
\text { I would consent to being contacted by the research team only after I have received } \\
\text { information about a study for which I was potentially eligible and agreed to be } \\
\text { contacted. }\end{array}$ & $\begin{array}{l}88(65) \\
74(54)\end{array}$ & $\begin{array}{l}20(15) \\
12(9)\end{array}$ & $\begin{array}{l}3(2) \\
5(4)\end{array}$ & $\begin{array}{l}25(18) \\
45(33)\end{array}$ \\
\hline $\begin{array}{l}\text { I would consent to be contacted by a research team directly if I am potentially } \\
\text { eligible for a study. }\end{array}$ & 7I (52) & II (8) & $12(9)$ & $42(3 I)$ \\
\hline
\end{tabular}

surprise that it did not exist already. Many patients thought it would be useful to be involved with a register.

I would have found this useful at the time, so I would support further work on this to help others. [Patient, Male, Acoustic Neuroma]

It is something that I would have expected to happen and was disappointed that there is not one as yet. [Patient, Female, LGG]
Patients or carers realize about the benefits of research and of a patient research register for them and future patients

A number of benefits were highlighted, including improving the quality of research and benefits for both current and future patients. Research benefits described included improving prognosis, examining the physical and psychological aspects of a diagnosis, and investigating the frequency of imaging undertaken. 
I understand that I am being monitored long term to keep an eye on changes to my condition but in these in between periods I would like to know that I am able to engage in anyway possible so that others could benefit from my experience, either with these surveys or being available for clinical trials. [Patient, Male, LGG]

Vital not only to improve the poor prognosis for such a high percentage of patients with a brain tumour but for more research into the physical and psychological effects of a diagnosis. [Patient, Female, Haemangioblastoma]

\section{Concerns of patients or carers on the creation of a patient research register was related to privacy and quality of the information recorded}

Patients mentioned the need to consider patients' privacy and the need to clearly specify inclusion criteria for a register, to collect all relevant information, and to ensure it is gathered from all relevant patients.

My only concerns would be about privacy. [Patient, Male, LGG]

\section{Potential areas for quality improvement}

A number of potential service improvement interventions were put to responders to determine their perceived utility. These included the provision of a digital system to enable health care professionals to seek specialist neuro-oncology input upon initial diagnosis (referral portal), the use of a patient-reported questionnaire for monitoring symptoms and concerns, and a patient-facing record detailing information on their condition and its management.

For the initial diagnosis phase, 107 (79\%) reported that they thought a referral portal would be useful at the initial stage of their care pathway. Most $(92,68 \%)$ of them also responded positively to the idea of a structured questionnaire, to allow the recording of their symptoms and concerns, taking place at their initial appointment (Table 5). Participants were asked the frequency at which they would be willing to undertake these. A total of 27 (20\%) participants were happy to complete these monthly, 39 (29\%) participants were happy to complete these 3 monthly, and 31 (23\%) participants were happy to complete these less frequently than 6 monthly. A small number of patients $(5,4 \%)$ were happy to complete these at the time of either a clinic appointment or scan.

A total of $100(74 \%)$ patients felt that a patient information record would be useful, reflecting the perceived difficulty with information provision and retention. When asked about specific content items, over $70 \%$ of responders thought that each of the following would be a useful component of a patient information record: specific information about diagnosis and treatment, information about symptoms and side effects of treatment, and information about future appointment and treatment, personalized plan, and key contacts.

\section{Discussion and conclusion Discussion}

We have conducted a UK-wide survey to determine patient perspectives on current neuro-oncology service provision across key phases of management. The survey was conducted through both workshops and online surveys, and within the limitations of a self-selecting sample, responses from a diverse patient cohort were achieved. We are aware that our purposive sample may not have included patients either unable or unwilling to attend the workshops or complete the online survey. It is therefore possible that certain issues related to these populations and their condition may have been under-represented, for example, those with significant cognitive and physical impairment. Nevertheless, our sample included a high proportion of carer responses, which could potentially act as surrogates for these patients. ${ }^{12}$ With the exception of an atypical gender ratio (male:female 3:7), other parameters (including age and tumor types) were otherwise in line with the reported values for patients with brain tumors. ${ }^{8}$ We are not aware of any reported gender differences in patient views on neuro-oncology care, and there is some evidence that gender does not seem to affect patient satisfaction in inpatient surgical care. ${ }^{14}$ We made no presumption of differ-

Table 5 Areas for further development

\begin{tabular}{|c|c|c|c|c|}
\hline \multirow[t]{2}{*}{ Question } & $\begin{array}{l}\text { Positive } \\
\text { response }\end{array}$ & $\begin{array}{l}\text { Neutral } \\
\text { response }\end{array}$ & $\begin{array}{l}\text { Negative } \\
\text { response }\end{array}$ & $\begin{array}{l}\text { No } \\
\text { response }\end{array}$ \\
\hline & n (\%) & n (\%) & n (\%) & n (\%) \\
\hline How useful would a direct referral portal be in improving time to diagnostic process? & $107(79)$ & $14(10)$ & $4(3)$ & II (8) \\
\hline $\begin{array}{l}\text { How useful would a structured questionnaire recording your symptoms and concerns } \\
\text { at your first appointment be? }\end{array}$ & $92(68)$ & $13(10)$ & $18(13)$ & $13(10)$ \\
\hline How useful would a patient information record be? & $100(74)$ & $6(4)$ & $\mathrm{I}(\mathrm{I})$ & $29(2 I)$ \\
\hline
\end{tabular}


ences in care requirements by tumor type as we set out to explore common issues across key phases of neuro-oncology care. The comprehensive nature of the survey across all tumor types and geographical locations enhances our knowledge of the current patient experience throughout their journey of the neuro-oncology service. It offers a unique perspective on practice implications by detailing patient views to potential service interventions and provides a platform for further disease-specific studies in this area.

The qualitative data included provided us with rich information about patient perceptions on their care. While much of this data confirmed the quantitative data from the survey, it allows contextualization of these results and further exploration of relationships impacting patient experience. While patient recall is likely to imperfect, given nearly onethird of responders were diagnosed 5 years or more ago, the findings are broadly in line with previous reports in this area. Combining both closed and open questions, alongside varying methods of survey completion, gives a more complete view of patient opinions. ${ }^{15}$

Despite a number of national surveys across cancer services demonstrating wide variations in care, ${ }^{8,9}$ there is little formally published literature on the subject within neurooncology. Outside of surveys, a previous study exploring patient views on general cancer care quality in a single region has reported considerable variation in service satisfaction despite an overall high baseline. ${ }^{16}$ Other studies investigating cancer patient experience demonstrated that similar issues shaped patients' experience across tumor types, although these translated into different service improvement priorities for each tumor. ${ }^{4}$ This highlights the need for tumor-specific studies.

Our results highlight a number of issues in the provision of care for patients with brain tumors. The high proportion of emergency presentations and multiple visits to health care services has been reported in epidemiological studies. ${ }^{17,18}$ This raises a number of issues; a number of patients deteriorate while waiting for clinical input and emergency presentations are associated with a lower 1-year survival, ${ }^{17,18}$ although at times emergency presentation is clearly unavoidable (eg, presentation with a first seizure). Improving time to diagnosis through evidence-based guidance for clinicians and public awareness may lessen the devastating impact that diagnosis of a brain tumor has on patients. ${ }^{19}$

While the process from referral to scan and subsequent initial visit was reported to happen in a timely manner, provision of information at this stage was felt to be limited. Concern was raised over information available prior to the scan and the understanding of the information provided prior to the initial visit at a neuroscience center. Information provision was also an issue following discharge, although some areas were covered well (information on diagnosis and treatment).

It is recognized that information provision throughout a cancer diagnosis can represent a logistical challenge and may arise as a result of the disease process itself. ${ }^{20}$ Previous suggestions to address this include patient-centered service organization and integration early in cancer care. ${ }^{21}$

We also found a mismatch between patient expectations of support following treatment and what was provided according to the responders. Perceived support was especially lacking in psychological and neuropsychology domains, in line with previous reports on brain tumor patients. ${ }^{20,22,23}$ It can be difficult to assess the care needs of cancer patients and a lack of concordance exists between function, symptoms, and needs, especially in those who are low functioning. ${ }^{24}$

Despite the reported gap in further support, there are limited recommendations on how this can be addressed. Previous reports have suggested the introduction of objective neuropsychology ${ }^{25}$ and quality-of-life assessments throughout the patient's journey ${ }^{26}$ as a mean of identifying potential issues early on and allowing intervention to establish support and coping mechanisms. Capturing quality-of-life data as a part of routine clinical care also provides an opportunity to develop research themes to improve the understanding of presenting symptoms and presentation mechanisms to facilitate more timely imaging and diagnosis and potentially to improve the survival and quality of life for brain tumor patients. ${ }^{18}$ Our results also suggest that patients would respond positively to the introduction of a referral portal, structured questionnaire at the initial appointment, and an information record as a practical mean of addressing existing gaps. These issues have also been raised through national initiatives, including four "calls to action" around getting a diagnosis, accessing treatment and services, improving people's quality of life, and receiving wider support services. ${ }^{9}$

The majority of patients and carers undertaking this survey showed an interest in on-going research and would be supportive of being included in a prospective research register. Inclusion of patient experience is crucial in both service improvement and on-going clinical trials. ${ }^{27}$ In other areas of research, for example, dementia, development of a research registry and networks has already been successfully implemented. ${ }^{28}$ These interventions have been shown to enhance research delivery within England and have led to a $600 \%$ increase in the number of people taking part in 
research studies. ${ }^{29}$ While the majority of patients in our cohort were not approached for participation in research, it is likely that a lack of clinical trials for which they are eligible may also have been a contributory factor. It follows therefore that the establishment of more clinical trials with broader inclusion criteria will be necessary in order for efforts aimed at increasing research participation, such as a patient register, to become effective.

\section{Conclusion and implications for practice}

This UK-based survey demonstrates significant variation in satisfaction with various aspects of neuro-oncology services. We have identified three potential key areas of improvement in current neuro-oncology services:

- Information provision,

- Access to support services,

- Inclusion in research.

These findings provide useful insight into potential quality improvement measures that can positively impact neurooncology services and are in line with other published studies reporting both the utility and effectiveness of such interventions. ${ }^{30-32}$ There is urgency in taking such potential initiatives forward, given that the delay in diagnosis of brain tumor is a common cause of medicolegal complaints and litigation. ${ }^{33}$

Potential measures to consider for addressing these gaps include

1. Establishment of a more streamlined and timely referral process through digital means that enables more interactive communication between different providers. ${ }^{34}$

2. Enhancing initial and follow-up assessments with routine quality-of-life measurement and health needs assessment. $^{35}$

3. Implementation of a patient-accessible portal providing tailored information resources and appropriate portions of the patient medical record. ${ }^{36}$

4. Creation of a comprehensive register to prospectively engage willing patients and carers in future relevant research. $^{28}$

\section{Acknowledgments}

This work was conducted within the DAMSEL project, cofunded by Innovate UK as a part of the Digital Health in a Connected Hospital initiative.

\section{Disclosure}

AJJ is the director of Obex Technologies Ltd, lead partner of the DAMSEL project consortium. AJJ, MB, and JDP are core members of the NIHR Brain Injury Health Technology Co-operative. AJJ is supported by an NIHR Academic Clinical Lectureship award. FMW is supported by an NIHR Clinical Scientist award. The authors report no other conflicts of interest in this work.

\section{References}

1. Heimans JJ, Taphoorn MJ. Impact of brain tumour treatment on quality of life. J Neurol. 2002;249(8):955-960.

2. Taphoorn MJ, Sizoo EM, Bottomley A. Review on quality of life issues in patients with primary brain tumors. Oncologist. 2010;15(6):618-626.

3. Stupp R, Hegi ME, van den Bent MJ, et al. Changing paradigms - an update on the multidisciplinary management of malignant glioma. Oncologist. 2006;11(2):165-180.

4. Tsianakas V, Robert G, Maben J, et al. Implementing patient-centred cancer care: using experience-based co-design to improve patient experience in breast and lung cancer services. Support Care Cancer. 2012;20(11):2639-2647.

5. Whitehouse M, Calman K. A policy framework for commissioning cancer services. BMJ. 1995;310(6992):1425-1426.

6. National Institute for Health and Clinical Excellence. Improving Outcomes for People with Brain and Other CNS Tumours. 2006. Cancer service guideline [CSG10]. Available from: https:/www.nice.org.uk/ guidance/csg10/resources/improving-outcomes-for-people-with-brainand-other-central-nervous-system-tumours-update-27841361437. Accessed January 11, 2019.

7. Guilfoyle MR, Weerakkody RA, Oswal A, et al. Implementation of neuro-oncology service reconfiguration in accordance with NICE guidance provides enhanced clinical care for patients with glioblastoma multiforme. Br J Cancer. 2011;104(12):1810-1815.

8. NHS England. Department of Health. Cancer patient experience survey 2015 - National Report. 2015. Available from: http://www.ncpes.co.uk/ reports/2015-reports/national-reports/2489-cpes-2015-national-reportpdf/file. Accessed January 11, 2019.

9. The Brain Tumour Charity. Finding a better way? Improving the quality of life for people affected by brain tumours. 2013

10. Brainstrust - what the brain cancer community needs. 2015. Available from: http://brainstrust.org.uk/wp-content/uploads/2017/09/what-thebrain-cancer-community-needs.pdf. Accessed January 11, 2019.

11. Anglia Cancer Network. Brain/CNS Patient Experience Survey report. 2013. Aud93/2103 v1.0 Available from: https://www.canceralliance. co.uk/download/0325534e-4a49-4029-94cd-d0e8191582f7. Accessed January 11, 2019.

12. Ediebah DE, Reijneveld JC, Taphoorn MJ, et al. Impact of neurocognitive deficits on patient-proxy agreement regarding health-related quality of life in low-grade glioma patients. Qual Life Res. 2017;26(4):869-880.

13. Elo S, Kyngäs $\mathrm{H}$. The qualitative content analysis process. J Adv Nurs. 2008;62(1):107-115.

14. Danforth RM, Pitt HA, Flanagan ME, Brewster BD, Brand EW, Frankel RM. Surgical inpatient satisfaction: what are the real drivers? Surgery. 2014;156(2):328-335.

15. The Health Foundation. Evidence scan: Measuring patient experience. 2013. Available from: https:/www.health.org.uk/publications/ measuring-patient-experience. Accessed January 11, 2019.

16. Davidson R, Mills ME. Cancer patients' satisfaction with communication, information and quality of care in a UK region. Eur J Cancer Care. 2005;14(1):83-90.

17. Lyratzopoulos G, Neal RD, Barbiere JM, Rubin GP, Abel GA. Variation in number of general practitioner consultations before hospital referral for cancer: findings from the 2010 National Cancer Patient Experience Survey in England. Lancet Oncol. 2012;13(4):353-365.

18. Lyratzopoulos G, Abel GA, Mcphail S, Neal RD, Rubin GP. Measures of promptness of cancer diagnosis in primary care: secondary analysis of national audit data on patients with 18 common and rarer cancers. Br J Cancer. 2013;108(3):686-690. 
19. Penfold C, Joannides AJ, Bell J, Walter FM. Diagnosing adult primary brain tumours: can we do better? Br J Gen Pract. 2017;67(659): 278-279.

20. Ford E, Catt S, Chalmers A, Fallowfield L. Systematic review of supportive care needs in patients with primary malignant brain tumors. Neuro Oncol. 2012;14(4):392-404.

21. Wagner EH, Aiello Bowles EJ, Greene SM, et al. The quality of cancer patient experience: perspectives of patients, family members, providers and experts. Qual Saf Health Care. 2010;19(6):484-489.

22. Janda M, Steginga S, Dunn J, Langbecker D, Walker D, Eakin E. Unmet supportive care needs and interest in services among patients with a brain tumour and their carers. Patient Educ Couns. 2008;71(2):251-258.

23. Schubart JR, Kinzie MB, Farace E. Caring for the brain tumor patient: family caregiver burden and unmet needs. Neuro Oncol. 2008;10(1):61-72.

24. Snyder CF, Garrett-Mayer E, Blackford AL, et al. Concordance of cancer patients' function, symptoms, and supportive care needs. Qual Life Res. 2009;18(8):991-998.

25. Janda M, Eakin EG, Bailey L, Walker D, Troy K. Supportive care needs of people with brain tumours and their carers. Support Care Cancer. 2006;14(11):1094-1103.

26. Velikova G, Awad N, Coles-Gale R, Wright EP, Brown JM, Selby PJ. The clinical value of quality of life assessment in oncology practice-a qualitative study of patient and physician views. Psychooncology. 2008;17(7):690-698.

27. Bate $P$, Robert G. Experience-based design: from redesigning the system around the patient to co-designing services with the patient. Qual Saf Health Care. 2006;15(5):307-310.
28. Iliffe S, Curry L, Kharicha K, et al. Developing a Dementia Research Registry: a descriptive case study from North Thames DeNDRoN and the EVIDEM programme. BMC Med Res Methodol. 2011;11(1):9.

29. Kotting P, Rossor MN, Mckeith IG, O'Brien JT, O'Brein JT. How dementia and neurodegenerative disease clinical research networks have enhanced research delivery in England. Clin Investig. 2014;4(8):687-691.

30. Langbecker D, Janda M. Systematic review of interventions to improve the provision of information for adults with primary brain tumors and their caregivers. Front Oncol. 2015;5:1

31. Boele FW, van Uden-Kraan CF, Hilverda K, et al. Neuro-oncology family caregivers' view on keeping track of care issues using eHealth systems: it's a question of time. J Neurooncol. 2017;134(1): 157-167.

32. Piil K, Jakobsen J, Juhler M, Jarden M. The feasibility of a brain tumour website. Eur J Oncol Nurs. 2015;19(6):686-693.

33. National Patient Safety Agency. Delayed diagnosis of cancer: Thematic review. 2010. Available from: https://patientsafety.health.org. uk/resources/delayed-diagnosis-of-cancer-thematic-review. Accessed January 11, 2019.

34. Chen AH, Murphy EJ, Yee HF. eReferral - a new model for integrated care. N Engl J Med. 2013;368(26):2450-2453.

35. Erharter A, Giesinger J, Kemmler G, et al. Implementation of computerbased quality-of-life monitoring in brain tumor outpatients in routine clinical practice. J Pain Symptom Manage. 2010;39(2):219-229.

36. Kruse CS, Argueta DA, Lopez L, Nair A. Patient and provider attitudes toward the use of patient portals for the management of chronic disease: a systematic review. J Med Internet Res. 2015;17(2):e40.
Cancer Management and Research

\section{Publish your work in this journal}

Cancer Management and Research is an international, peer-reviewed open access journal focusing on cancer research and the optimal use of preventative and integrated treatment interventions to achieve improved outcomes, enhanced survival and quality of life for the cancer patient. The manuscript management system is completely online and includes

\section{Dovepress}

a very quick and fair peer-review system, which is all easy to use. Visit http://www.dovepress.com/testimonials.php to read real quotes from published authors. 